\title{
The Power to Hurt: Costly Conflict with Completely Informed States
}

\author{
BRANISLAV L. SLANTCHEV University of California, San Diego
}

\begin{abstract}
$B$ ecause war is costly and risky, states have incentives to negotiate and avoid conflict. The common rationalist explanation is that war results from private information and incentives to misrepresent it. By modeling warfare as a costly bargaining process, I show that inefficient fighting can occur in equilibrium under complete information and very general assumptions favoring peace. Specifically, I assume that peace can be supported in equilibrium and that fighting brings no benefits to either state, only costs. Although there exist agreements that Pareto-dominate the final settlement, states may prefer to fight. The result turns on the ability of states to impose costs on their opponents and bear costs in return. The existence of a range of acceptable settlements and the threat to revert to particularly disadvantageous ones make inefficient equilibria possible. A diminished ability to hurt the enemy, not simply military victory, is a major reason to stop fighting.
\end{abstract}

W hy do wars occur? Because fighting is always inefficient ex post, it should be possible to design an agreement that both sides would accept in lieu of going to war and negotiating thereafter. Fearon (1995) conceptualized war as bargaining failure and identified rationalist explanations of this puzzle: Possessing private information about one's capabilities and incentives to misrepresent it during negotiations can lead to bargaining failure, as can the inability to commit not to use one's current gains to extract further concessions in the future. ${ }^{1}$

Two crucial assumptions underlie these explanations: Common models treat crisis negotiation as a singleshot bargaining event, and war as a costly lottery over exogenously fixed outcomes. These assumptions, however, are problematic as approximations of war as usually conceptualized by practitioners and historians. A classic statement in this regard is that of von Clausewitz $(1832,87)$, who argued that "war [...] always lasts long enough for influence to be exerted on the goal and for its own course to be changed in one way or another." Schelling $(1966,7)$ is blunt: "War [is] a bargaining process-dirty, extortionate, and often quite reluctant as a bargaining process on one side or both-nevertheless a bargaining process." Modeling conflict using the two common assumptions misses the point that war is a process in which players can condition their strategies depending on past play. Recent formal theoretical advances have begun to address these issues. Although closer to nonformal treatments, they still depend on asymmetric information to explain conflict. $^{2}$

Posing the question in terms of a bargaining process that occurs in the shadow of fighting is useful in

Branislav L. Slantchev is Assistant Professor of Political Science, University of California, San Diego, 9500 Gilman Drive, La Jolla, CA 92093-0521 (slantchev@ucsd.edu).

This article is a shorter version of the first chapter of my dissertation. I thank Randall Stone, Curt Signorino, John Duggan, and Robert Westbrooke for valuable comments. Previous versions were presented to the Peace Science Society, October 2001, and the Midwest Political Science Association, April 2002.

${ }^{1}$ Although there are several works that explain conflict as a dynamic commitment problem (e.g., Powell 1997), it is the asymmetric information argument that seems to have received most attention.

2 See Filson and Werner 2001, Kim 2001, Powell 2001, Smith and Stam 2001, and Wagner 2000. addressing the related puzzle of war termination: If fighting is costly, why do the sides delay in reaching a settlement to end it? ? $^{3}$ Most wars end not in complete military victory that eliminates the opponent's ability to continue fighting, but in some negotiated settlement (Pillar 1983). Focusing on victory and defeat, as the costly lottery approach does, can therefore be misleading in this respect as well.

I model war as a process instead of an outcome and allow outcomes to be endogenous. One of the goals is to examine the strategic incentives for inefficient behavior in the absence of asymmetric information, especially as it relates to ending costly conflict. To this end, I stack the model against war by making several assumptions: (i) peace can be supported in equilibrium; (ii) peace is the most preferred outcome; (iii) fighting produces costs and no direct benefits; and (iv) there is complete information. Therefore, in this model war is not profitable by assumption. I find that even under these strict assumptions there exist inefficient equilibria, in which fighting occurs. This provides another plausible explanation of why states may fight despite the inefficiency.

Once war is disaggregated from a lottery over exogenous outcomes into a process where war aims arise endogenously, it is possible to make a subtle distinction between two types of costs that are associated with conflict: the ability to bear costs and the ability to impose costs. To my knowledge, there exists no theory in international relations, either formal or nonformal, that alludes to such a difference or that is even capable of conceptualizing it within its framework. ${ }^{4}$ This distinction

\footnotetext{
${ }^{3}$ There are relatively few works on this topic. General ones include Dunnigan and Martel 1987, Iklé 1971, Kecskemeti 1958, Kegely and Raymond 1999, and Smith 1995. Two recent interesting empirical works are Goemans 2000 and Stam 1999.

${ }^{4}$ These abilities are related but not isomorphic. That is, it is not the case that state A's ability to impose costs on state B is the same as state B's ability to bear costs. This is because state A must in turn incur costs when it imposes costs on B, which determines the extent to which A can hurt B. These costs are not entirely dependent on B's defenses because they depend on other factors, such as A's domestic politics or international situation. During the Vietnam war, the American administration proscribed bombing certain targets, such as irrigation installations, which could have proven effective in imposing costs on Hanoi. This was a result of Johnson's well-founded fear that it could draw China into the war.
} 
is relevant because it induces bargaining strategies that produce outcomes that cannot be predicted from the usual models.

These results draw attention to two underappreciated areas in research on war: the endogeneity of war aims and the ability of states to inflict pain on their adversaries. Although coercion has been recognized as perhaps the premier instrument of wartime politics, theories of war have generally ignored the possibilities that states condition negotiation strategies on their performance in the war and that such strategies depend on their ability to impose costs in unforeseen ways.

Uncertainty is a pervasive feature of international politics, and almost all models in which war occurs in equilibrium rely on asymmetric information to explain war (Powell 2001). As Goemans (2000, 24) notes, "If both sides knew how the pie would be divided after the war, both would be better off if they divided accordingly before the war." 5 However, simply knowing how the pie would be divided does not necessarily mean that the division is the only one that can be supported in equilibrium ex ante even if such outcome is preferable because it is Pareto-improving (that is, at least one player can be made better off without anyone else being made worse off). Inefficiency can occur under complete information because (i) a range of negotiated agreements can be supported as outcomes of efficient equilibria; (ii) some of these leave players distinctly worse off; and (iii) the threat to switch to one of these different equilibria, depending on the path of play, can support a variety of inefficient equilibria that involve fighting.

The result of inefficiency under complete information has much in common with several formal models of wage bargaining in economics. These models have also normally invoked asymmetric information as the cause of delay and suboptimal outcomes, but there have been several recent developments. Fernandez and Glazer (1991) study a complete information model in which a firm and a union bargain over wages and in which the union can go on strike. They are able to demonstrate that inefficient equilibria exist in which the union strikes (see also Haller and Holden 1990). Unlike such a model, in which only one player can impose costs on the other, I allow both players to engage in a conflict game after any offer is rejected.

My approach is similar to that of Busch and Wen (1995), who study a more general model, where a disagreement game is embedded in a Rubinstein (1982) bargaining game. They also demonstrate that inefficient behavior can occur when the disagreement game, which is played after an offer is rejected, meets certain conditions. Muthoo (1999), on whose work my analysis relies heavily, provides a slightly different version of some proofs. I extend these models by allowing players to have different discount rates, which turns out to be a nontrivial assumption. In addition to this extension,

\footnotetext{
5 This is almost identical to Fearon's (1995, 380-88) conclusion.
}

which is of interest for theoretical reasons, my discussion of the substantive implications points to areas that are not developed (or even recognized) in much of the literature on international relations.

\section{THE MODEL}

Consider two states, $i \in\{1,2\}$, that are bargaining over a two-way partition of a flow of benefits with size $\pi$. An agreement is a pair $\left(x_{1}, x_{2}\right)$, where $x_{i}$ is state $i$ 's share. The set of possible pairs is

$$
\begin{gathered}
\mathcal{X}=\left\{\left(x_{1}, x_{2}\right) \in \mathcal{R}^{2}: x_{1}+x_{2}=\pi \text { and } 0 \leq x_{i} \leq \pi\right. \\
\text { for } i=1,2\} .
\end{gathered}
$$

States have strictly opposed preferences and each is concerned only with the share of benefits it obtains from the agreement. A status quo distribution of benefits, $\left(s_{1}, s_{2}\right)$ with $s_{1}+s_{2}=\pi$, exists prior to any agreement. Because a share $x_{i}$ in a proposal identifies a distribution uniquely, I write $x_{1}$, which is equivalent to the pair $\left(x_{1}, \pi-x_{1}\right)$, and $x_{2}$, which is equivalent to the pair $\left(\pi-x_{2}, x_{2}\right)$.

The two players bargain according to the alternatingoffers protocol. Players act in discrete time with a potentially infinite horizon, with periods indexed by $t(t=0,1,2, \ldots)$. Players have time preferences with constant interest rates, so the discount factors are $\delta_{i} \in(0,1)$. In even-numbered periods, player 1 proposes a division $x_{1} \in \mathcal{X}$ to player 2 . If player 2 accepts that proposal, an agreement is reached, and players obtain their share in $\left(x_{1}, \pi-x_{1}\right)$, respectively, in every following period.

If player 2 rejects the proposal, then both states play the conflict game $\Gamma$. The description of this game is abstract. Let $\Gamma$ be some game in normal form where each player $i$ has an action space $A_{i}$. Given a profile of actions $\left(a_{1}, a_{2}\right)$ with $a_{1} \in A_{1}$ and $a_{2} \in A_{2}$, the player's payoff is $r_{i}\left(a_{1}, a_{2}\right)$.

To stack the model against fighting, assume that (i) peace is one of the outcomes in $\Gamma$; (ii) peace is the most preferred outcome for both players - that is, fighting is costly and brings no benefits to either player in $\Gamma$; and (iii) peace is a subgame perfect equilibrium (SPE) of $\Gamma$. Let the peace payoff to player $i$ be its share of the status quo distribution of benefits. If either player attacks, any outcome results in some payoff strictly less than the peace payoff. The payoffs for the worst outcome are normalized to 0 . Thus, for all $a_{1} \in A_{1}, a_{2} \in A_{2}$, $r_{i}\left(a_{1}, a_{2}\right) \in\left[0, s_{i}\right]$, where the payoff $s_{i}$ is obtainable only if neither player fights in $\Gamma$. The payoffs in the conflict game constitute per-period payoffs in the bargaining game.

After $\Gamma$ finishes, time advances to the next period where player 2 makes a counteroffer, $x_{2} \in \mathcal{X}$. Player 1 can either accept it, in which case the players obtain $\left(\pi-x_{2}, x_{2}\right)$, respectively, or reject it, in which case they play $\Gamma$ again. The game continues until an agreement is reached. Figure 1 shows the schematic for two periods of the negotiation game. Each state's objective is to maximize its average intertemporal 


\section{FIGURE 1. Two Periods of the Negotiation Game}

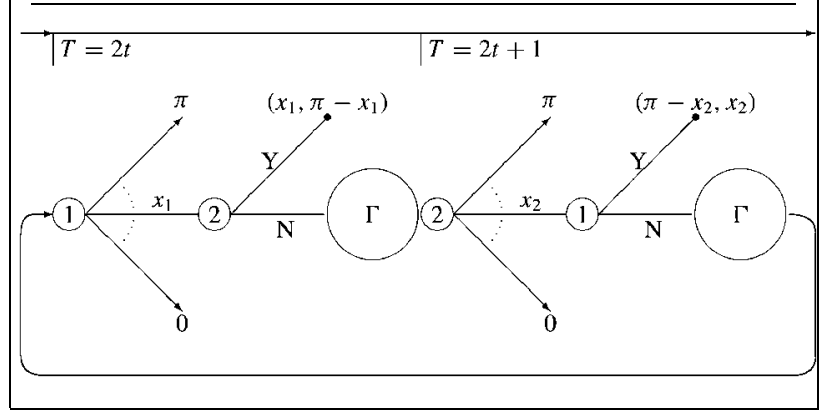

payoff $\left(1-\delta_{i}\right) \sum_{t=0}^{\infty} \delta_{i}^{t} z_{i t}$, where $z_{i t}$ is state $i$ 's perperiod payoff at time $t$ and equals its share of the benefits if an agreement is reached or $r_{i t}$ otherwise.

Since Nash equilibria may rely on noncredible threats, the solution concept I use is that of subgame perfect equalibrium SPE, which is a refinement of Nash in that it requires each player's strategy to be optimal in every proper subgame, whether or not this subgame is ever reached when players follow their strategies (Selten 1975). In other words, an equilibrium is subgame perfect if the strategies it induces are a Nash equilibrium in every subgame.

\section{EFFICIENT EQUILIBRIA: THE THREAT TO HURT}

An SPE in the bargaining game is stationary if players always make the same proposals regardless of history and time. An SPE is no-delay if a player's equilibrium proposal is immediately accepted by the other player. Assume that if a player is indifferent between accepting a proposal and continuing the game, it accepts the proposal. The following proposition establishes the existence of stationary efficient equilibria. ${ }^{6}$

Proposition 2.1. For each SPE of $\Gamma$, the bargaining game has a unique stationary no-delay SPE in which, for $i, j \in\{1,2\}$ and $i \neq j$, state $i$ always proposes $x_{i}^{*}$, accepts $x_{j} \leq x_{j}^{*}$, rejects $x_{j}>x_{j}^{*}$, and chooses its SPE strategy $a_{i}^{*}$ in $\Gamma$, and where

$$
x_{i}^{*}=r_{i}^{*}+\left(1-\delta_{j}\right) w,
$$

with $r_{i}^{*} \equiv r_{i}\left(a_{1}^{*}, a_{2}^{*}\right)$ and $w=\left(\pi-r_{1}^{*}-r_{2}^{*}\right) /\left(1-\delta_{1} \delta_{2}\right) \geq$ 0 . The outcome in all cases is that agreement is reached immediately on the division $\left(x_{1}^{*}, \pi-x_{1}^{*}\right)$ and no fighting occurs.

Because the peace outcome is an SPE of $\Gamma$, this proposition implies that the bargaining game has at least one stationary no-delay SPE (SSPE), which is efficient: Agreement is reached immediately at $t=0$ and no fighting occurs.

\footnotetext{
${ }^{6}$ The analysis relies heavily on Muthoo 1999 , which is in turn based on Busch and Wen 1995. Proposition 2.1 is an adapted version of Proposition 6.5 in Muthoo's (1999) book, and the proof requires only straightforward modifications.
}

Corollary 2.2. The status quo distribution $\left(s_{1}, s_{2}\right)$ can be supported in SSPE.

Although this game has efficient peaceful equilibria, they are not the only ones. Any inefficient SPE involves some playing in $\Gamma$ that is not Nash. The analysis that follows is analogous to the standard "equilibrium switching" method commonly used to establish Folk Theorems for repeated games (Fudenberg and Maskin 1986). ${ }^{7}$ First, I show that a minimum payoff smaller than the status quo can be supported in an efficient equilibrium. Then I show how the threat to revert to the efficient SPE that yields this payoff to the deviating party can keep states from deviating in inefficient equilibria, i.e., equilibria in which costly fighting occurs for nonzero periods of time.

Because payoffs are time-invariant, all subgames that begin with a proposal by player $i$ are structurally identical, which implies that the sets of SPE are the same. Let $G_{i}$ denote a subgame that begins with a proposal by player $i$. Because any outcome that involves conflict is, by assumption, worse than peace, state 2 can keep state 1 strictly below its status quo payoff by fighting in $\Gamma$. We can therefore define the minimax payoffs of $\Gamma$ as follows.

Definition 2.1. Let $v_{1}=\min _{a_{2}} \max _{a_{1}} r_{1}\left(a_{1}, a_{2}\right)<s_{1}$ be player 1's worst payoff that player 2 can impose. Define $\underline{v}_{2}<s_{2}$ analogously.

Denote an arbitrary Nash equilibrium of $\Gamma$ by $\sigma^{*}$ and note that $\underline{v}_{i} \leq r_{i}\left(\sigma^{*}\right) \leq \bar{v}_{i}$. Because peace can be produced by an SPE in $\Gamma$, I define two relevant action profiles.

Definition 2.2. Let $\underline{\sigma} \equiv\left(\underline{a}_{1}, \underline{a}_{2}\right)$ be an action profile in $\Gamma$ such that $r_{1}(\sigma)=\underline{v}_{1}$. Let $\bar{\sigma} \equiv\left(\bar{a}_{1}, \bar{a}_{2}\right)$ be the SPE in $\Gamma$, such that $\bar{v}_{i}=s_{i}$.

Because any player can attack in the conflict game and fighting is costly, it follows that $\underline{v}_{i}<s_{i}=\bar{v}_{i}$. I now turn to the main proposition of this section, which establishes that player 1's worst (respectively, player 2's best) payoff can be supported in SPE. The proof is in the Appendix.

Proposition 2.3 (Extremal SPE). With sufficiently little discounting, the following hold.

1. If $\delta_{1} \geq \delta_{2}$, the following strategies support an $S P E$ in which agreement $\left(x_{1}^{*}, \pi-x_{1}^{*}\right)$ is obtained immediately.

(A) Player 1 always offers $x_{1}^{*}=\underline{v}_{1}+\left(1-\delta_{2}\right) w_{1}$, accepts $x_{2} \leq x_{2}^{*}$, and rejects $x_{2}>x_{2}^{*}$, where $w_{1}=\left(\pi-\underline{v}_{1}-\bar{v}_{2}\right) /\left(1-\delta_{1} \delta_{2}\right)$. Player 2 always offers $x_{2}^{*}=\bar{v}_{2}+\left(1-\delta_{1}\right) w_{1}$, accepts $x_{1} \leq x_{1}^{*}$, and rejects $x_{1}>x_{1}^{*}$. If player 1 rejects an offer, then play $\sigma$ in $\Gamma$, and if player 2 rejects an offer, then play $\bar{\sigma}$. If player 2 offers $x_{2}>x_{2}^{*}$, rejects

\footnotetext{
${ }^{7}$ It is relatively easy to obtain inefficient outcomes in repeated games. The model of war as a bargaining process, however, is not a repeated game because agreement ends it, and the standard Folk Theorems therefore do not apply.
} 
$x_{1} \leq x_{1}^{*}$, or plays differently in $\Gamma$, then switch to phase $B$.

(B) Play the SSPE from Corollary 2.2.

2. If $\delta_{1} \leq \delta_{2}$, the following strategies support an SPE in which agreement is obtained only in $G_{2}$.

(A) Player 1 always makes nonserious offers $\left(\right.$ e.g., $\left.x_{1}^{*}=\pi\right)$, accepts $x_{2} \leq x_{2}^{*}$, and rejects $x_{2}>x_{2}^{*}$. Player 2 always offers $x_{2}^{*}=\left(1+\delta_{1}\right)^{-1}\left(\pi-\underline{v}_{1}+\delta_{1} \bar{v}_{2}\right), \quad$ accepts $x_{1} \leq$ $\underline{x}_{1}=\left(1+\delta_{1}\right)^{-1}\left(\bar{v}_{1}+\delta_{1} \underline{v}_{1}\right)$, and rejects $x_{1}>\bar{x}_{1}$. If player 1 rejects an offer, then play $\sigma$ in $\Gamma$, and if player 2 rejects an offer, then play $\bar{\sigma}$. If player 2 offers $x_{2}>x_{2}^{*}$, rejects $x_{1} \leq x_{1}$, or plays differently in $\Gamma$, then switch to phase $B$.

(B) Play the SSPE from Corollary 2.2.

In a Type I equilibrium from Proposition 2.3, when $\delta_{2}$ becomes sufficiently high, the equilibrium payoff converges to $\underline{v}_{1}$, which is the smallest payoff from $\Gamma$. The strategies do not support an equilibrium if $\delta_{1}<\delta_{2}$. However, notice that when $\delta_{1}=\delta_{2}$ both equilibria are payoffequivalent, implying that in a Type II equilibrium and with sufficiently high $\delta_{1}$, the payoff is arbitrarily close to the payoff from a Type I equilibrium.

Proposition 2.3 highlights two important features of the bargaining model. First, regardless of the relationship of the two discount factors, it is possible to sustain in equilibrium payoffs that are strictly smaller than the peaceful SSPE from Corollary 2.2. This is an essential result because the threat to revert to an extremal SPE (ESPE) with the low payoff is sufficient to support fighting in equilibrium, as the next section demonstrates. Second, this proposition illustrates that the common assumption of equal discount factors is not harmless. Although intuitively one should expect the results to depend on how the two players value the future, and especially on whether their valuations diverge, bargaining models often assume away the difference. The richness of this model, however, introduces a level of complexity that must somehow be reduced. I now examine the implications of the two types of extremal SPE identified by Proposition 2.3 and how a player's smallest payoff differs between them.

\section{INEFFICIENT EQUILIBRIA: THE FEAR OF SETTLEMENT}

Consider player 1's smallest and largest sustainable payoffs. If $\delta_{1} \geq \delta_{2}$, then, using Type I ESPE, the smallest payoff obtained immediately in a subgame beginning with player 1 's offer is

$$
\underline{v}_{1}+\frac{1-\delta_{2}}{1-\delta_{1} \delta_{2}}\left(\pi-\underline{v}_{1}-\bar{v}_{2}\right)=\underline{v}_{1}+\frac{1-\delta_{2}}{1-\delta_{1} \delta_{2}}\left(\bar{v}_{1}-\underline{v}_{1}\right)
$$

Because player 2's smallest payoff that can be supported by a Type II ESPE is $\left(1+\delta_{2}\right)^{-1}\left(\bar{v}_{2}+\delta_{2} \underline{v}_{2}\right)$, the largest payoff that player 1 can get is

$$
\pi-\frac{\bar{v}_{2}+\delta_{2} \underline{v}_{2}}{1+\delta_{2}}=\bar{v}_{1}+\frac{\delta_{2}\left(\bar{v}_{2}-\underline{v}_{2}\right)}{1+\delta_{2}} .
$$

If $\delta_{1}<\delta_{2}$, then, using Type II ESPE, the smallest payoff obtained in games beginning with player 1's offer is

$$
\left(1-\delta_{1}\right) \bar{v}_{1}+\delta_{1}\left(\pi-x_{2}^{*}\right)=\frac{\bar{v}_{1}+\delta_{1} \underline{v}_{1}}{1+\delta_{1}} .
$$

Note that the payoff includes the first term because agreement is obtained only in the subgame that begins with player 2's offer. Because player 2's smallest payoff that can be supported by a Type I ESPE is $\underline{v}_{2}+\left(1-\delta_{1} \delta_{2}\right)^{-1}\left(1-\delta_{1}\right)\left(\bar{v}_{2}-\underline{v}_{2}\right)$, the largest payoff that player 1 can get is

$$
\pi-\underline{v}_{2}-\frac{\left(1-\delta_{1}\right)\left(\bar{v}_{2}-\underline{v}_{2}\right)}{1-\delta_{1} \delta_{2}}=\bar{v}_{1}+\frac{\delta_{1}\left(1-\delta_{2}\right)}{1-\delta_{1} \delta_{2}}\left(\bar{v}_{2}-\underline{v}_{2}\right) \text {. }
$$

To condense these results to manageable definitions, let player 1's minimum payoff that can be sustained in ESPE be

$\underline{s}=\left\{\begin{array}{lll}\underline{v}_{1}+\left(1-\delta_{1} \delta_{2}\right)^{-1}\left(1-\delta_{2}\right)\left(\bar{v}_{1}-\underline{v}_{1}\right) & \text { if } & \delta_{1} \geq \delta_{2}, \\ \left(1+\delta_{1}\right)^{-1}\left(\bar{v}_{1}+\delta_{1} \underline{v}_{1}\right) & \text { if } & \delta_{1}<\delta_{2},\end{array}\right.$

and let player 1's maximum payoff that can be sustained in ESPE be

$$
\bar{s}= \begin{cases}\bar{v}_{1}+\left(1+\delta_{2}\right)^{-1} \delta_{2}\left(\bar{v}_{2}-\underline{v}_{2}\right) & \text { if } \quad \delta_{1} \geq \delta_{2}, \\ \bar{v}_{1}+\left(1-\delta_{1} \delta_{2}\right)^{-1} \delta_{1}\left(1-\delta_{2}\right)\left(\bar{v}_{2}-\underline{v}_{2}\right) & \text { if } \quad \delta_{1}<\delta_{2} .\end{cases}
$$

Claim 3.1. $\underline{s}<\bar{s}$ for all $\delta_{1}, \delta_{2} \in(0,1)$.

Proof. Consider the case $\delta_{1} \geq \delta_{2}$. Because for any $\delta_{1}<1, \quad \alpha \equiv\left(1-\delta_{1} \delta_{2}\right)^{-1}\left(1-\delta_{2}\right)<1$, it follows that $\alpha \bar{v}_{1}+(1-\alpha) \underline{v}_{1}<\bar{v}_{1}$, where the inequality follows from $\bar{v}_{1}>\underline{v}_{1}$. Thus, $\underline{s}<\bar{v}_{1}$ for all $\delta_{1}<1$. Moreover, $\bar{s}>\bar{v}_{1}$ from (2) because the second term is positive. Therefore, $\underline{s}<\bar{s}$, as required.

Consider now the case $\delta_{1}<\delta_{2}$. Because $\underline{s}<\bar{v}_{1}$ for any $\delta_{1}>0$, and $\bar{s}>\bar{v}_{1}$ for any $\delta_{2}<1$, the result is established.

With these results, I now state the principal result.

Proposition 3.1 (Inefficient SPE). For any distribution of benefits $s \in(\underline{s}, \bar{s})$, some period $\tau>0$, and sufficiently little discounting, equilibria of the following type exist: In all periods $t=(0,1, \ldots, \tau-1)$, both players make nonserious offers, reject all proposals, and fight in $\Gamma$. In period $\tau$, they agree on the distribution $(s, \pi-s)$. If either player deviates, then immediately play the ESPE from Proposition 2.3 that supports that player's smallest payoff.

Proof. Recall that the payoff from each player's worst outcome from fighting is normalized to 0 . If player 1 follows the proposed strategy, then its payoff is at least $\delta_{1}^{\tau} s$. If it deviates in some $t<\tau$, then its payoff is at most $\left(1-\delta_{1}^{t}\right) \bar{v}_{1}+\delta_{1}^{t} \underline{s}$, which in the limit, as $\delta_{1} \rightarrow 1$, converges to $\underline{s}<s$. Thus, for sufficiently high $\delta_{1}$, deviation is not profitable. The proof for player 2 is equivalent, mutatis mutandis.

Although many agreements would be Paretoimproving (such as $s$ reached in periods prior to $\tau$ ), 
these settlements cannot be had because of the way players respond to deviations. It is the threat to revert to an efficient SPE, which yields the potential deviator its worst possible payoff, that sustains these inefficient equilibria. The result does not disappear when the time between periods becomes arbitrarily small, as is usually the case with bargaining models. This is because shortening the periods between offers not only makes alternation faster, but also decreases the costs that players suffer due to fighting. Players still fight because not doing so means obtaining a worse settlement. There is no incomplete information in the model, so fighting cannot serve as a signal to separate types. Thus, even with quickly alternating offers, equilibria exist with delays in reaching an agreement. This inefficiency is contrary to the so-called Coase (1972) Conjecture in economics, which posits that even with incomplete information the ability to alternate offers quickly should produce agreements without costly delay.

It is worth noting that there are other equilibria in which fighting is sporadic, and they are all supported by similar strategies. As Busch and Wen (1995) note, strategic interaction outside the bargaining process will generally generate multiple equilibria. This indeterminacy makes empirical testing difficult. However, as my purposes are to demonstrate a logical result and point to a mechanism that is neglected in explanations of conflict, this is no great handicap.

\section{DISCUSSION}

The range of distributions supportable in an inefficient SPE varies with the costs of fighting. From equation (1), it is evident that $\underline{s}$ is increasing in player 1's minimax payoff $\underline{v}_{1}$. Thus, when the cost of fighting decreases, so that player 1 can guarantee itself a higher payoff during conflict, the lower bound on possible agreements increases, improving player 1's worst-case payoff. This result is hardly surprising and is consistent with findings supporting the conclusion that decreasing the costs of fighting improves a state's bargaining position.

From equation (2), the upper bound on possible agreements is decreasing in $\underline{v}_{2}$. In other words, as player 2's minimax payoff increases, player 1's best payoff decreases. Because the minimax payoff is by definition the worst payoff that player 1 can impose on player 2, it follows that the capacity to impose costs on its opponent improves player 1's bargaining position by expanding the upper bound on the range of agreements.

This highlights an important aspect of conflict: The ability to bear costs associated with the opponent's effort to inflict pain influences how much a state can be expected to give up in a bargain. The capacity to inflict pain on the opponent, determined by the ability to bear costs associated with this effort, influences how much a state can demand in a bargain. Thus, the two types of costs jointly determine the bargaining range that opens up during fighting.

The capacity to hold the enemy to its smallest (minimax) payoff and the magnitude of costs a state must pay when the enemy is holding it to its smallest (minimax) payoff emerge as central elements in the explanation for war. The bargaining strategies that depend on fighting behavior and these costs can result in equilibria that may explain many puzzling cases, such as those where states have given up fighting after suffering relatively minor casualties or continued fighting in the face of mounting losses.

For example, in 1940 the French surrendered Paris to Germany after suffering about 90,000 dead and 250,000 wounded. This was the same nation that had defended the fortress of Verdun in 1916 at the cost of about 400,000 casualties against the same enemy (Keegan 1999, esp. 71-137). The crucial difference was that, unlike its effect in the First World War, the German onslaught in the Second managed to destroy the organizational capacity of the French high command and damaged beyond repair the French ability to inflict substantial losses on the Germans (May 2000).

Facing circumstances in which fighting is hopeless because it cannot induce the other side to accept a settlement makes surrender a rational choice. On the other hand, the continued resistance of North Vietnam despite the heavy toll extracted by the United States can also be explained by the ability of North Vietnam to cause enough damage to induce their opponent to withdraw. Similarly, the Afghani rebels could outlast the Soviet occupational forces despite heavy casualties for essentially the same reasons, as demonstrated by the immediate damaging effect of Gorbachev's glasnost on the Russian popular support for the war.

Continuing with the French surrender, it is instructive to note that the French government retained some residual power to inflict costs on the Germans. It could choose to flee to Algiers and continue to direct the war from there, a prospect Hitler recognized and wanted to avoid. On one hand, the Germans had devastated the French military to the point where France could not expect to inflict enough pain on the Third Reich to secure more benefits (the upper bound on the possible agreement was very low). On the other, the residual capacity to fight meant that the Germans could have been made to pay more unless they offered something (the lower bound on agreements was higher than zero).

This concession turned out to be the French fleet, which the Germans promised not to appropriate for wartime use. Perhaps surprisingly, this was the rare promise that Hitler kept. How important this concession was is illustrated by Britain's reaction to the deal. Churchill was so apprehensive that the Germans would use the captured fleet in their war on the isle nation that, after the French refused either to scuttle it or to put it to a British port, he ordered it bombed, which the Royal Air Force promptly did.

The process of war can be usefully viewed as a contest, in which both sides attempt to reduce the opponent's ability to impose costs on them while simultaneously trying to impose costs on the opponent, thereby improving their own bargaining position. Although destroying personnel and materiél may be conducive to diminishing state capacity to fight, it is not necessarily the optimal way of doing so. If a state is weak and/or cannot gain access to the opponent's homeland, 
its recourse may be to attempt outlasting the enemy. No country, even the richest, can sustain an indefinite involvement in war. Therefore, if a state can deny the opponent the power to hurt and simultaneously inflict enough damage to cause the enemy to expand its economic and troop involvement, then even a weaker state has good chances of success.

Three central implications emerge from this analysis. First, states may fight as long as they believe that seeking peace prematurely means accepting an unpalatable settlement. I should emphasize that in the model presented here, it is not the threat to use force, but the realization of the power to hurt, or the compellent use of force, that is important (Art 1980). As Schelling $(1966,3)$ notes, "Unhappily, the power to hurt is often communicated by some performance of it." However, it is not that states are unsure about each other's power (after all, this is a model of complete information). Rather, it is their commitment to particular strategies that produces the unhappy outcome. As in the familiar Prisoner's Dilemma, the strategies that result in the bad outcome are best responses to each other, so states cannot improve the outcome by deviating and, for example, not fighting. The problem is precisely the existence of efficient, but less preferable, bargains and the fact that if a state does not fight, then it will have to accept a diplomatic solution it likes least.

The rationale for forming such expectations empirically can be justified on the basis of a limited information argument that involves signaling behavior. Standard arguments from signaling models demonstrate that players can use costly actions to signal privately known parameters, such as cost and resolve, to other players. In such an environment, states can conceivably prolong the fight to convince their opponents about privately held information. In particular, they might choose to fight when they believe that if they quit to make an offer instead, their opponent would interpret this as a revelation of weakness and exploit it by demanding more. A logic roughly analogous to this operates in the full information model, the only difference being that states know exactly what worse bargain they will have to accept if they deviate from the fighting strategy. It is worth noting that this is one possible way to arrive at such strategies. Others, such as public opinion and the anticipation of the effect of this opinion, can also be invoked.

Second, the diminished or eliminated capacity to hurt the enemy is a major reason to terminate war and seek a negotiated settlement. This is a far cry from conventional notions of victory and defeat because it may not involve the complete destruction of the opponent, only of its ability to retaliate. Ho Chi Minh stated, "You can kill ten of my men for every one I kill of yours. But even at those odds, you will lose and I will win." The key in this statement is not, as usually interpreted, the Vietnamese willingness to suffer, although this undoubtedly played a role (Rosen 1972). ${ }^{8}$ Rather, it is their ability to kill one

\footnotetext{
${ }^{8}$ Rosen incorrectly implies "American" soldiers when Ho had referred to the French.
}

American soldier even if it took 10 Vietnamese to do so. The Vietnamese correctly surmised that this power to hurt would eventually compel the United States to withdraw. It is doubtful that such a policy would have succeeded had the United States been able to limit the number of casualties and expenses.

Schelling (1966) observed that "the power to hurt $[\ldots]$ is a kind of bargaining power." Although as a rule formal models of conflict feature the costs of war as an explanatory variable, and despite the prominent role of that variable in solutions, it is always state ability to bear costs that is discussed, but not state capacity to impose costs on others. The costs associated with these actions are analytically distinct and not necessarily related in a straightforward manner.

Third, because the power to hurt is a kind of bargaining power, the denial of such power undermines the bargaining position of the opponent. It is partially for these reasons that the NATO aerial attacks on Kosovo could succeed. Even the most determined opponent would yield if there were no way to hurt the enemy and thus influence the outcome of negotiations. In some respects, this argument also shows why a ground invasion would have been ill advised: The mountainous terrain, very much unlike the desert in the Persian Gulf, would not have allowed the easy application of NATO military superiority. There can be no question about the eventual outcome of such an engagement, but it is quite possible that mounting casualties might have tempted the United States into a more accommodating position. Stam (1999) estimates that the probability of success of a ground invasion was $49 \%$ and argues that this is why it was not attempted. I find the argument doubtful. Even if the probability of success were $100 \%$, a ground invasion would have entailed significant casualties and, thus, given Belgrade bargaining power. Air strikes were ideal precisely because they denied Milosevic the power to hurt NATO forces and, thus, maneuver Yugoslavia into a better position at the negotiation table. This also illustrates why Saddam Hussein's plan "to draw the Coalition into a premature ground offensive in the hope that heavy casualties would lead Western publics to demand an early ceasefire" could not work (Pape 1996, 357).

These three points are interconnected insofar as fighting is a way to influence the final outcome, but as such, it depends on the power to hurt the opponent. It is useful to explore several historical cases in some detail to see how this logic operated in causing the termination of war and in influencing the form of settlements. These cases are only illustrations and serve as checks on the plausibility of the arguments developed here.

First, the Japanese decision to surrender in August 1945 is shown to have arisen, at least in part, from the realization that the military was unable to inflict sufficient damage on the U.S. forces in a land invasion. Second, I also examine the Vietnam War, showing that because both sides expected to have to accept worse settlements should they stop fighting, they continued the costly conflict until the United States was forced to quit due to domestic pressure (the threat of reversion to an efficient but unpalatable agreement). These cases 
illuminate certain features of the model and are useful examples of how the causal logic might work in practice. I do not claim that the model provides a complete explanation, only that it reveals a mechanism and a relationship that are often neglected.

\section{Japan's Surrender in 1945}

Japan's decision to surrender in 1945 provides a good example of the complex interaction between the (loss of) power to hurt and the expectations for a better settlement. ${ }^{9}$ Significantly, at the time of surrender Japan still had over 2 million men armed and ready to fight. Neither the incendiary raids on the major cities nor the nuclear attacks had undermined morale to any perceptible degree. ${ }^{10}$ Moreover, despite the Allied success in "Operation Iceberg," which captured Okinawa, the major islands still remained in Japanese hands. The unconditional ${ }^{11}$ surrender on August 15 is thus a rare instance of a nation capitulating before most of its home territory had been conquered and while an army still existed that could potentially defend it.

Foreign Minister Togo began the peace overtures in late spring through the Japanese Moscow ambassador by trying to get the Soviets to mediate with the Allies. Although Stalin was not forthcoming with the information, the United States was aware of the approach. However, even after the direct message of the July 12 cable, which stated the Emperor's desire to end the war, no positive steps were taken in that direction. Togo urged the continuation of the war in an effort to improve the diplomatic situation (Butow 1954, 77-78).

Japan was in a precarious position by the early summer. Admiral Suzuki had become Prime Minister on April 6, but his attempts to find a way to conclude the war did not have enough support in the cabinet where, despite the bitter divisions, the hawks still held the upper hand. It is arguable that it may have been possible to bring about an earlier surrender through a more assertive action, but the undisputed fact remains that War Minister Anami and the Army Chief of Staff Umezu were formidable opponents very much opposed to cessation of hostilities. On June 6, the document entitled "The Fundamental Policy to Be Followed Henceforth in the Conduct of War" was introduced in the Supreme Council. It flatly called for continuation of fighting in the homeland, stating that this was the only way to preserve the nation. Few believed that Japan could turn the tide of Allied victory, but many thought that an operational success would provide a better basis to negotiate a settlement. In fact, this possibility "became

\footnotetext{
${ }^{9}$ For a recent authoritative discussion, see Sigal 1988. Two other classic studies are Brooks 1968 and Butow 1954. For an analysis of the factors that contributed to the decision to surrender and an evaluation of competing explanations, see Pape 1996. For an argument about the psychological impact of the atomic bomb, see Asada 1998 ${ }^{10}$ Although there was some absenteeism from work due to massive flight from the cities, as a whole industrial workers turned up at about the same rate as in the United States (Pape 1996, 129-30).

11 The omission of the Emperor's fate from the Potsdam Declaration has been routinely interpreted as the Allies implicitly agreeing to his retention.
}

a key point in the military's demand to continue the war through an Allied invasion of the home islands" (Butow 1954, 93-96).

This policy stemmed from the conviction that despite enormous expected Japanese losses, the Allies would also be badly hurt (Kennedy 1983, 193). Thus, the idea was not to defeat U.S. forces militarily (such a thing was "beyond all expectation," as General Miyazaki admitted), but to "inflict tremendous losses, forcing [the enemy] to realize the strong fighting spirit of the Japanese Army and people [and thus] bring about the termination of hostilities on comparatively favorable terms."12 The success of this strategy clearly depended on the ability of the Army to inflict the necessary amount of damage.

The illusory nature of this hope was revealed by two events: The atomic bomb dropped on Hiroshima on August 6 and the Soviet declaration of war on August 9 (intercepted at dawn). The militarists, who had refused to convene the Supreme Council after the destruction of Hiroshima when Togo and Suzuku wanted to meet urgently (Asada 1998, 488), now agreed to discuss whether Japan should accept the Potsdam declaration. ${ }^{13}$ Even then Umezu claimed that "we would be able to inflict extremely heavy damage on the enemy," but Togo clearly did not believe it, and it is doubtful that the General believed it himself (Brooks 1968, 62-63). Upon hearing the news about the debacle of the Manchurian army, Suzuki remarked, "Is the Kwantung army that weak? Then the game is up" (Brooks 1968, 17). The unexpected but complete collapse of what was supposed to be the elite Japanese fighting force finally convinced even the staunchest militarists that their hopes of inflicting sufficient casualties in a ground invasion of the main islands were wishful thinking.

It is worth noting that the timing of this meeting undermines the standard claim that the nuclear bomb was the main factor in the Japanese decision to surrender. The people who were seeking ways to terminate the war simply used it as another reason that the Army's plan was impossible to implement. The militarists, on the other hand, either refused to believe the news or simply ignored it. While the Council was debating whether the United States had more than one bomb at its disposal, the news of Nagasaki arrived, enhancing further the claims of the peace party. However, "the news of the Nagasaki bombing notwithstanding, a heated argument continued" (Asada 1998, 492) and it required two more meetings for the decision to be accepted. Anami claimed that "the appearance of the atomic bomb does not spell the end of war.... We are confident about a decisive homeland battle against American forces" but then went on to admit that "given the atomic bomb and the Soviet entry, there is no chance of winning on the

\footnotetext{
${ }^{12}$ Lieutenant General Arisue. His and Miyazaki's statements are in Sigal 1988, 228.

13 The atomic bomb moved Emperor Hirohito toward decisive action but the army still would not budge, claiming that Hiroshima had been destroyed not by a nuclear weapon but by a "conventional bomb with extraordinary destructive power” (Asada 1998, 485).
} 
basis of mathematical calculation" (finally concluding that a fanatical and hopeless fight to save the Yamato race was the only remaining option) (Asada 1998, 494). Thus, despite the importance of the atomic bomb argument, it was the Soviet intervention, which the Japanese had anticipated with trepidation ever since Stalin repudiated the prewar nonaggression pact, that precipitated the crucial reevaluation of the situation. ${ }^{14}$

Despite claims to the contrary, credible estimates of the number of U.S. casualties for an invasion of Kyushu, one of the home islands, range between 63,000 and $100,000 .{ }^{15}$ Some apprehensiveness was caused by the loss in the Okinawa campaign, which took the heaviest toll of the war in the Pacific, and it was used as an early excuse for the atomic bomb (especially by an euphoric Churchill, who called it "a miracle of deliverance"). However, the firm stand that the Allies took with respect to Japanese demands to negotiate terms reveals that they were prepared to bear this cost to secure unconditional surrender.

Thus, although a party sought the termination of war early on, its efforts were thwarted by the hardliners, who believed that Japan had sufficient capability to defend the home islands. Much of Japanese intransigence in the face of overwhelming odds depended on the belief in their remaining power to hurt the United States sufficiently to soften the terms of surrender. As Kecskemeti (1958) points out, the residual capacity to impose costs on the victor makes negotiation desirable by both sides before the ultimate showdown. In August 1945, the Japanese military finally seems to have realized that estimates of their ability to inflict pain on the United States were fantastically exaggerated. The entry of the USSR into the war and the consequent collapse of the vaunted Kwantung Army were perhaps the momentous events that revealed the hollow hopes of the "hawks." This provided enough ammunition for peace-seekers to overcome the opposition to unconditional surrender and finally end the war.

This case illustrates the logic of fighting to impose costs to obtain a better settlement even when the prospects of military victory are dim. While the formal model shows why such a plan can work, the complete information requirement postulates that players are actually able to engage in costly fighting. The Japanese

\footnotetext{
14 Kecskemeti (1958) reaches the same conclusion about the impact of Stalin's declaration, but for different reasons. He contends that the Soviet entry in the war dispelled the last illusions the Japanese had of using Stalin as a mediator for extracting better terms from the Americans and thereby forced them to accept whatever was being offered. This seems to require a whole lot of unwarranted hoping by the Japanese high command, especially since Stalin had refused to renew the prewar nonaggression pact earlier in the year, had promised to enter the Pacific War several months after concluding the war in Europe, and could be expected to want to take part in the division of the spoils in Asia.

15 There is a common belief that the dogged defense of Iwo Jima and Okinawa caused the United States to update its beliefs about the costs of invasion, which in turn precipitated the use of the atomic bombs (Giangreco 1997; MacEachin 1998). However, as the military commanders argued, complete victory was a foregone conclusion (Miles 1985). The military buildup on Kuyshu may have altered the initial cost estimates and may even have prevented operation Olympic in favor of some alternative against northern Honshu (Bernstein 1999).
}

abandoned the strategy when they realized that they did not have the ability to inflict enough pain on the Allies. The model cannot account for this event, but it illuminates the strategic thinking that led first to the decision to stand firm and then to the reason why it was abandoned. The next case is one where the strategy did work as planned.

\section{The Vietnam War}

Recall that the inefficient (fighting) equilibrium is supported by strategies that require a deviating player to "suffer" the worst acceptable agreement. The Vietnam War illustrates a case in which both sides believed that ending hostilities early would give the other an undue negotiating advantage. The leitmotif of the engagement under Johnson was that neither side made serious attempts to begin negotiations (recall that in the inefficient equilibrium, both sides make nonserious offers throughout the war). Both the United States and North Vietnam wanted to secure enough battlefield success to ensure a favorable outcome of diplomacy. However, the Jason Study indicated as early as 1966 that bombing had no measurable impact on the agricultural economy of North Vietnam and was unlikely to succeed in breaking Vietnamese morale. The Enthoven report of 1967 was even more frank in concluding that the Vietnamese strategy was to keep their losses at "a level low enough to be sustained indefinitely, but high enough to tempt us to increase our forces to the point of U.S. public rejection of the war" (Karnow 1983, 519).

General Giap, the principal architect of the 1968 Tet offensive, had a long-range strategy whose principal objective "was to continue to bleed the Americans until they agreed to a settlement that satisfied the Hanoi regime" (Karnow 1983, 549). The U.S. antiwar movement had played only a secondary role in Giap's planning but, once discovered, was explited to the full as an the additional means to impose costs on the United States. Giap remarked in the 1990s that he wanted to demonstrate "that if Vietnamese blood was being spilled, so was American blood [...] and more and more Americans renounced the war" (Karnow 1983, 557).

As Pape (1996, 177-94) concluded, the failure of Rolling Thunder's (1965-68) alternation among a Schelling strategy of increasing risk to Hanoi's industrial base, a denial by interdiction, and a Douhet plan that focused on increasing current costs was due simply to North Vietnam's low vulnerability to these types of coercion strategies. It was not until 1972, when Hanoi switched to conventional warfare (which was militarily vulnerable to U.S. bombing), that coercive air power could compel them to return to the negotiating table. However, even then Kissinger's first attempt failed when South Vietnam's Thieu refused to sign the agreement. The North Vietnamese used this as a pretext to back out of negotiations, which precipitated Nixon's "Christmas" bombing (Linebacker II) to break the deadlock and the attempt to blackmail a better agreement. 
The Communists considered battlefield victories the "key factor 'for the attainment of a political settlement" "and believed that they could force the United States out by breaking its ties with the Saigon regime and exploiting the antiwar movement. Nixon was convinced that quitting unconditionally would spell the end of Saigon and perhaps his own reputation and that it would damage the U.S. international position. Despite Nixon's claims that the United States had "finally achieved peace with honor," the Paris treaty of 1973 was an admission of defeat. Although the North Vietnamese demand for a coalition government was dropped, the agreement allowed their troops to remain in the South and virtually guaranteed the overthrow of Saigon that occurred two years later.

The U.S. administration firmly believed that it could not quit the war because leaving Communist aggression unchecked would encourage similar movements elsewhere. It also worried about U.S. political standing in the international arena, especially with regard to its European allies (Strong 1992, 93-94). However, relentless bombing could not coerce Hanoi into negotiations, and the domestic situation was hardly favorable for a full-scale land invasion. Saigon could not exist without U.S. support, Vietnamization had failed, and the war had no end in sight. The ability of the United States to hurt North Vietnam was severely limited by the guerilla tactics of the Viet Cong, the agricultural economy (which, unlike industrialized economies, cannot be hurt by destroying identifiable objects), the unsophisticated (and easily repairable) infrastructure, the constant influx of supplies from the USSR and China, and the politically motivated limitations placed upon the military. ${ }^{16}$

On the other hand, North Vietnam's power to hurt the United States increased with time and the extent of U.S. involvement in the war. The war was costly, in both economic and humanitarian terms. The fearsome combination of rising taxes and a climbing death toll was the nightmare of the administration, which was also harangued by the antiwar demonstrators. Without prospects of winning or the means to coerce Hanoi, the United States could do little more than withdraw. Even though both sides believed that quitting early would give undue advantage to the enemy, the power to hurt rested with North Vietnam, and so did the eventual settlement.

\section{CONCLUSION}

I have argued that it is misleading to regard war as a costly lottery over exogenously fixed outcomes. After noting that both practitioners of war and scholars have posited that war is a kind of bargaining process, I constructed a stylized model that incorporates the simultaneous occurrence of negotiation and fighting to allow players to condition their strategies on their past behavior. I completely stacked the model against

\footnotetext{
$\overline{16}$ George Ball's memo to Johnson (July 1,1965$)$ is fairly incisive with respect to the prospects of victory and the costs of alternative outcomes. Excerpts are given in Strong 1992, 108-9.
}

conflict by assuming that peace can be supported in equilibrium and that fighting brings only costs and no benefits to both sides.

Despite these fairly generous assumptions about peace, inefficient fighting can occur in equilibrium and there may be a delay in reaching an agreement. This result does not require incomplete information and does not depend on any of the mechanisms from standard rationalist explanations of war. Instead, war becomes possible when states utilize conditional strategies that make war aims dependent on actions in the model.

The existence of these inefficient equilibria depends on two types of costs of war. The first is the cost that a state can be made to pay when its opponent tries to hurt it. The second is the cost that a state must pay to hurt its opponent. The power to hurt, which turns on the relative magnitude of these costs, and the conditional strategies open up a bargaining range that can produce fighting in equilibrium under complete information.

The power to hurt should not be treated in simple military terms. Throughout Napoleon's wars, England, which kept raising and resurrecting coalition after coalition against him, was his principal enemy (Fuller 1961, 55-56). Without a means of striking at the island itself, Napoleon resolved to strangle it economically, fully aware that if he could hurt British exports, he would undermine their credit and their ability to pay for the wars against him. The Continental System was designed for precisely that purpose. Lacking a capability to hurt his main enemy through direct miliary engagement, Napoleon correctly inferred that his troubles would never be over unless he found another way of doing so: The System was the weapon to do it. Thus, the power to hurt can take many forms, from military victory, to economic coercion, and humanitarian losses.

The idea that the power to hurt may not translate directly into factors commonly used to measure force, such as military capabilities, geopolitical configurations, economic resources, and features of the political system, provides further clues as to why costly conflict may erupt between sides with severe power asymmetries (e.g., the conflict between Israel and the Palestinians). These conclusions also put in doubt common statistical models of war, which rely on aggregate military and economic capabilities of states. As demonstrated by the empirical cases, these rough indicators may be completely wrong in predicting outcomes. The power to hurt can take many forms.

\section{APPENDIX}

\section{Proof of Proposition 2.3}

This establishes the result for the extremal SPE that support player 1's worst payoff. The result for player 2 follows from a symmetric argument. The optimality of phase B in both cases follows from Proposition 2.1.

Consider player 1's strategy in $\Gamma$. Suppose player 1 has rejected an offer. Given that player 2 is minimaxing, player 1 cannot profitably deviate. Suppose player 2 has rejected an offer. Since next period 2 offers $\pi-x_{2}^{*}$ regardless of 1's actions in $\Gamma$, where the proposed strategy yields the highest 
payoff of $\bar{v}_{1}$ there, no deviation is profitable. Thus, the rule for player 1's actions in $\Gamma$ is optimal.

Case 1: $\delta_{1} \geq \delta_{2}$. Consider player 1's strategy in $G_{1}$. Following the proposal rule yields $x_{1}^{*}$. Player 1 will not deviate by offering $x_{1}<x_{1}^{*}$ because player 2 accepts such offers. Suppose player 1 deviates with $x_{1}>x_{1}^{*}$, which player 2 rejects. Player 1's payoff from such deviation is $\left(1-\delta_{1}\right) \bar{v}_{1}+$ $\delta_{1}\left(\pi-x_{2}^{*}\right) \leq \underline{v}_{1}+\left(1-\delta_{2}\right) w_{1}=x_{1}^{*}$. Because this inequality holds when $\delta_{1} \geq \delta_{2}$, such deviation is not profitable. Thus, the proposal rule is optimal.

Consider player 1's strategy in $G_{2}$. Suppose player 1 responds to some $x_{2}<x_{2}^{*}$ by deviating and rejecting. Its payoff will be $\left(1-\delta_{1}\right) \underline{v}_{1}+\delta_{1} x_{1}^{*}=\pi-x_{2}^{*}<\pi-x_{2}$ and, hence, not profitable. Suppose now player 1 has to respond to some $x_{2}>x_{2}^{*}$, in which case the game switches to phase B. If player 1 follows the proposed strategy, the payoff is at least $\left(1-\delta_{1}\right) \underline{v}_{1}+\delta_{1}\left[\underline{v}_{1}+\left(1-\delta_{2}\right) w_{1}\right]=\pi-x_{2}^{*}>\pi-x_{2}$. Hence, player 1 cannot profitably deviate by accepting. Thus, the acceptance rule is optimal.

Since this exhausts all possible subgames, the proposed strategy for player 1 is a best response to player 2's strategy.

Consider player 2's strategy in $\Gamma$. If it follows the proposed strategy, the payoff in the next period is $\min \left\{x_{2}^{*}, \pi-x_{1}^{*}\right\}=\pi-x_{1}^{*}$. Therefore, 2's payoff from following the strategy is at least

$$
\left(1-\delta_{2}\right) r_{2}(\underline{\sigma})+\delta_{2}\left[\bar{v}_{2}+\frac{\delta_{2}\left(1-\delta_{1}\right)}{1-\delta_{1} \delta_{2}}\left(\pi-\underline{v}_{1}-\bar{v}_{2}\right)\right] .
$$

If player 2 deviates, then the game switches to phase $\mathrm{B}$, where player 2's payoff is $s_{2}$. Hence, the deviation payoff is at most $\bar{v}_{2}$. As $\delta_{2} \rightarrow 1$, the expression in (3) converges to $\pi-\underline{v}_{1}>\pi-\bar{v}_{1}=\bar{v}_{2}$. Therefore, for each $\delta_{1}$ sufficiently high, there exists $\delta_{2}^{\prime} \leq \delta_{1}$ such that for all $\delta_{2} \in\left[\delta_{2}^{\prime}, \delta_{1}\right]$ deviation is not profitable. Thus, the rule for play in $\Gamma$ is optimal.

Consider player 2's strategy in $G_{2}$. If player 2 follows the proposed strategy, the payoff is $x_{2}^{*}$. Player 2 will not deviate by offering $x_{2}<x_{2}^{*}$ because player 1 accepts all such offers. Suppose player 2 deviates and offers some $x_{2}>x_{2}^{*}$. Player 1 always rejects such proposals and the game switches to phase B. Player 2's payoff from such deviation is at most

$$
\left(1-\delta_{2}\right) r_{2}(\underline{\sigma})+\delta_{2} s_{2}<\bar{v}_{2},
$$

where the inequality follows from $r_{2}(\underline{\sigma})<\bar{v}_{2}$. Since $x_{2}^{*}$ is strictly greater than (3), it follows that there exists some $\delta_{2}^{\prime \prime} \in(0,1)$ such that for all $\delta_{2} \in\left(\delta_{2}^{\prime \prime}, 1\right), x_{2}^{*}$ is strictly greater than (4). Hence, such deviation is not profitable. Taking $\underline{\delta}_{2}=\max \left\{\delta_{2}^{\prime}, \delta_{2}^{\prime \prime}\right\}$ yields the discount factor for the proposition. Thus, the proposal rule is optimal.

Consider player 2's strategy in $G_{1}$. Suppose player 1 offers some $x_{1}<x_{1}^{*}$. If player 2 follows the proposed strategy and accepts, the payoff is

$$
\bar{v}_{2}+\frac{\delta_{2}\left(1-\delta_{1}\right)}{1-\delta_{1} \delta_{2}}\left(\pi-\underline{v}_{1}-\bar{v}_{2}\right) .
$$

If it deviates and rejects, the game switches to phase $\mathrm{B}$, and its best payoff is $\bar{v}_{2}$, which is smaller than (5) and, therefore, strictly smaller than $\pi-x_{1}$. Hence, such deviation is not profitable. Suppose that now player 1 offers some $x_{1}>x_{1}^{*}$. If player 2 follows the proposed strategy and rejects, the payoff is $\bar{v}_{2}+\delta_{2}\left(1-\delta_{1}\right) w_{1}>\pi-x_{1}$, where the last term is the (unprofitable) deviation payoff from accepting. Thus, the acceptance rule is optimal.

Since this exhausts all possible subgames, the proposed strategy for player 2 is a best response to player 1's strategy. Therefore, the strategies stated in the proposition indeed constitute an SPE of the bargaining game.
Case 2: $\boldsymbol{\delta}_{\mathbf{1}} \leq \boldsymbol{\delta}_{\mathbf{2}}$. Consider player 1's strategy in $G_{1}$. Given player 2's strategy, if player 1 always makes nonserious offers and rejects all proposals, then it can guarantee a payoff of $\bar{v}_{1}$ in any period, which begins with its offer, and $\underline{v}_{1}$ in any period, which begins with player 2's offer. Thus, player 1 can get at least $\left(1-\delta_{1}\right)\left(\bar{v}_{1}+\delta_{1} \underline{v}_{1}+\delta_{1}^{2} \bar{v}_{1}+\delta_{1}^{3} \underline{v}_{1}+\cdots\right)=(1+$ $\left.\delta_{1}\right)^{-1}\left(\bar{v}_{1}+\delta_{1} \underline{v}_{1}\right) \equiv \underline{x}_{1}$. Since player 2 only accepts $x_{1} \leq \underline{x}_{1}$, player 1 cannot improve its payoff from making a proposal that will be accepted. Therefore, player 1's strategy of making a nonserious offer is optimal.

Consider player 1's strategy in $G_{2}$. Suppose player 2 offers $x_{2} \leq x_{2}^{*}$. Since it is not the case that $x_{2}^{*}<\left(1+\delta_{1}\right)^{-1}(\pi-$ $\left.\underline{v}_{1}+\delta_{1} \bar{v}_{2}\right)$, it cannot be profitable for player 1 to deviate and reject. Suppose player 2 offers $x_{2}>x_{2}^{*}$, in which case the game switches to phase B. If player 1 deviates and accepts, the payoff is $\pi-x_{2}<\pi-x_{2}^{*}=(1+$ $\left.\delta_{1}\right)^{-1}\left(\underline{v}_{1}+\delta_{1} \bar{v}_{1}\right) \leq\left(1-\delta_{1}\right) \underline{v}_{1}+\delta_{1} \bar{v}_{1}$, and so such deviation is not profitable. Therefore, the acceptance rule is optimal.

Since this exhausts all possible subgames, the proposed strategy for player 1 is a best response to player 2's strategy. I now show that player 2's strategy is also optimal.

Consider player 2's strategy in $\Gamma$. If it deviates, the game switches to phase $\mathrm{B}$, so the maximum payoff is $\left(1-\delta_{2}\right) \bar{v}_{2}+\delta_{2} \bar{v}_{2}=\bar{v}_{2}$. If player 2 follows the proposed strategy, then the payoff is at least $\left(1-\delta_{2}\right) r_{2}(\sigma)+\delta_{2}\left[\left(1-\delta_{2}\right) \bar{v}_{2}+\right.$ $\left.\delta_{2} x_{2}^{*}\right]$. As $\delta_{2} \rightarrow 1$, this converges to $x_{2}^{*}>\bar{v}_{2}$. Therefore, there exists $\delta_{2}^{\prime} \in(0,1)$ such that for all $\delta_{2} \in\left(\delta_{2}^{\prime}, 1\right)$, deviation is not profitable. Thus, the rule for play in $\Gamma$ is optimal.

Consider player 2's strategy in $G_{1}$. Since player 1 never offers $x_{1}<x_{1}$, player 2 must decide whether to reject some $x_{1} \geq \underline{x}_{1}$. Because $\delta_{1} \leq \delta_{2}$, it follows that it is not the case that $\pi-\underline{x}_{1}>\left(1-\delta_{2}\right) \bar{v}_{2}+\delta_{2} x_{2}^{*}$, and so player 2 cannot profitably deviate by accepting the offer. Suppose that now player 1 offers some $x_{1} \leq \underline{x}_{1}$. If player 2 follows the proposed strategy and accepts, the payoff is

$$
\begin{aligned}
\pi-x_{1} & \geq \pi-\underline{x}_{1}=\left(1+\delta_{1}\right)^{-1}\left[\bar{v}_{2}+\delta_{1}\left(\pi-\underline{v}_{1}\right)\right] \\
& >\left(1+\delta_{1}\right)^{-1}\left(\bar{v}_{2}+\delta_{1} \bar{v}_{2}\right)=\bar{v}_{2} .
\end{aligned}
$$

If it deviates and rejects, then the game switches to phase B, where the payoff is $\bar{v}_{2}$. Hence, the largest deviation payoff is $\left(1-\delta_{2}\right) \bar{v}_{2}+\delta_{2} \bar{v}_{2}=\bar{v}_{2}$, which is not profitable. Thus, the acceptance rule is optimal.

Consider player 2's strategy in $G_{2}$. If it follows the proposed strategy, the payoff is $x_{2}^{*}$. Deviation by offering $x_{2}<x_{2}^{*}$ is not profitable because player 1 accepts all such offers. Suppose player 2 deviates by offering $x_{2}>x_{2}^{*}$, which player 1 always rejects. Since the game switches to phase $\mathrm{B}$, the payoff then is $\left(1-\delta_{2}\right) r_{2}(\underline{\sigma})+\delta_{2} \bar{v}_{2} \leq \bar{v}_{2}$. But since $\underline{v}_{1}<\bar{v}_{1} \Rightarrow \pi-\underline{v}_{1}>\pi-\bar{v}_{1}=\bar{v}_{2}$, we have $x_{2}^{*}=$ $\left(1+\delta_{1}\right)^{-1}\left(\pi-\underline{v}_{1}+\delta_{1} \bar{v}_{2}\right)>\bar{v}_{2}$. Hence, deviation is not profitable. Thus, the proposal rule is optimal.

Since this exhausts all possible subgames, the proposed strategy for player 2 is a best response to player 1's strategy. Therefore, the strategies stated in the proposition constitute an SPE of the bargaining game. Note that any offer $x_{1}>x_{1}$ will be rejected by player 2 , and therefore there exists a continuum of SPE, in which player 1 makes different nonserious offers. All these SPE are payoffequivalent.

\section{REFERENCES}

Art, Robert J. 1980. "To What Ends Military Power." International Security 4 (Spring): 4-35. 
Asada, Sadao. 1998. "The Shock of the Atomic Bomb and Japan's Decision to Surrender-A Reconsideration." Pacific Historical Review 477-512.

Bernstein, Barton J. 1999. "The Alarming Japanese Buildup on Southern Kuyshu, Growing U.S. Fears, and Counterfactua Analysis: Would the Planned November 1945 Invasion of Southern Kuyshu Have Occurred?" Pacific Historical Review 561-609.

Brooks, Lester. 1968. Behind Japan's Surrender: The Secret Struggle that Ended an Empire. New York: McGraw-Hill.

Busch, Lutz-Alexander, and Quan Wen. 1995. "Perfect Equilibria in a Negotiation Model." Econometrica 63 (May): 545-65.

Butow, Robert J. C. 1954. Japan's Decision to Surrender. Stanford, CA: Stanford University Press.

Coase, Ronald. 1972. "Durability and Monopoly." Journal of Law and Economics 15 (April): 143-49.

Dunnigan, James F., and William Martel. 1987. How to Stop a War: The Lessons of Two Hundred Years of War and Peace. New York Doubleday.

Fearon, James D. 1995. "Rationalist Explanations for War." International Organization 49 (Summer): 379-414.

Fernandez, Raquel, and Jacob Glazer. 1991. "Striking for a Bargain Between Two Completely Informed Agents." American Economic Review 81 (March): 240-52

Filson, Darren, and Suzanne Werner. 2001. "Bargaining and Fighting: The Impact of Regime Type on War Onset, Duration, and Outcomes." Paper presented at the Political Economy of Conflict Conference, Yale University, March 23-24.

Fudenberg, Drew, and Eric Maskin. 1986. "The Folk Theorem in Repeated Games with Discounting or with Incomplete Information.' Econometrica 54 (May): 533-54.

Fuller, J. F. C. 1961. The Conduct of War, 1789-1961. New Brunswick, NJ: Rutgers University Press.

Giangreco, D. M. 1997. "Casualty Projections for the U.S. Invasions of Japan, 1945-1946: Planning and Policy Implications.” Journal of Military History 61 (July): 521-82.

Goemans, Hein E. 2000. War and Punishment: The Causes of War Termination and the First World War. Princeton, NJ: Princeton University Press.

Haller, Hans H., and Steinar Holden. 1990. "A Letter to the Editor on Wage Bargaining." Journal of Economic Theory 52: 232-36.

Iklé, Fred Charles. 1971. Every War Must End. New York: Columbia University Press.

Karnow, Stanley. 1983. Vietnam: A History. New York: Penguin Books.

Kecskemeti, Paul. 1958. Strategic Surrender: The Politics of Victory and Defeat. Stanford, CA: Stanford University Press.

Keegan, John. 1999. The First World War. New York: Knopf

Kegely, Charles W., Jr., and Gregory A. Raymond. 1999. How Nations Make Peace. New York: St. Martin's Press.

Kennedy, Paul. 1983. Strategy and Diplomacy, 1870-1945. London: George Allen \& Unwin.
Kim, Dong-Won. 2001. "Bargaining, Conflict, and War." Texas Tech University. Mimeo.

MacEachin, Douglas J. 1998. The Final Months of the War with Japan Signals Intelligence, U.S. Invasion Planning, and the A-Bomb Decision. Washington, DC: Central Intelligence Agency.

May, Ernest R. 2000. Strange Victory: Hitler's Conquest of France. New York: Hill \& Wang.

Miles, Rufus E., Jr., 1985. "Hiroshima: The Strange Myth of Half a Million American Lives Saved." International Security 10 (Fall): 121-40.

Muthoo, Abhinay. 1999. Bargaining Theory with Applications. Cambridge: Cambridge University Press.

Pape, Robert A. 1996. Bombing to Win: Air Power and Coercion in War. Ithaca, NY: Cornell University Press.

Pillar, Paul R. 1983. Negotiating Peace: War Termination as a Bargaining Process. Princeton, NJ: Princeton University Press.

Powell, Robert. 1997. "Bargaining in the Shadow of Shifting Power." Paper presented at the annual meeting of the American Political Science Association, Washington, DC, August 28-31.

Powell, Robert. 2001. "Bargaining While Fighting." University of California, Berkeley. Mimeo. October 7, 2001, version.

Rosen, Steven. 1972. War Power and the Willingness to Suffer. In Peace, War, and Numbers, ed. Bruce M. Russett. Beverly Hills: Sage, 167-83.

Rubinstein, Ariel. 1982. "Perfect Equilibrium in a Bargaining Model." Econometrica 50: 97-110.

Schelling, Thomas C. 1966. Arms and Influence. New Haven, CT: Yale University Press.

Selten, Reinhard. 1975. "Reexamination of the Perfectness Concept for Equilibrium Points in Extensive Games." International Journal of Game Theory 4 (1): 25-55.

Sigal, Leon V. 1988. Fighting to a Finish: The Politics of War Termination in the United States and Japan, 1945. Ithaca, NY: Cornell University Press.

Smith, Alastair, and Alan C. Stam, III. 2001. "Bargaining Through Conflict." Paper presented at the Annual Meeting of the Public Choice Society, San Antonio, TX, March 8-10.

Smith, James D. D. 1995. Stopping Wars: Defining the Obstacles to Cease-Fire. Boulder, CO: Westview Press.

Stam, Alan C., III. 1999. Win, Lose, or Draw: Domestic Politics and the Crucible of War. Ann Arbor: University of Michigan Press.

Strong, Robert A. 1992. Decisions and Dilemmas: Case Studies in Presidential Foreign Policy Making. Englewood Cliffs, NJ: Prentice Hall.

von Clausewitz, Carl. 1832. On War. Princeton, NJ: Princeton University Press. Edited and translated by Michael Howard and Peter Paret, 1984.

Wagner, R. Harrison. 2000. "Bargaining and War." American Journal of Political Science 44 (July): 469-84. 